\title{
openheart 180 -day readmission risk model for older adults with acute myocardial infarction: the SILVER-AMI study
}

John A Dodson (D , , ${ }^{1,2}$ Alexandra M Hajduk, ${ }^{3}$ Terrence E Murphy, ${ }^{3}$ Mary Geda, ${ }^{3}$ Harlan M Krumholz, ${ }^{4,5,6,7}$ Sui Tsang, ${ }^{3}$ Michael G Nanna, ${ }^{8}$ Mary E Tinetti, ${ }^{3}$ Gregory Ouellet, ${ }^{3}$ Deborah Sybrant, ${ }^{9}$ Thomas M Gill, ${ }^{3}$ Sarwat I Chaudhry ${ }^{10}$

\begin{abstract}
- Additional material is published online only. To view, please visit the journal online (http://dx.doi.org/10.1136/ openhrt-2020-001442).
\end{abstract}

To cite: Dodson JA, Hajduk AM, Murphy TE, et al. 180-day readmission risk model for older adults with acute myocardial infarction: the SILVER-AMI study Open Heart 2021;8:e001442. doi:10.1136/

openhrt-2020-001442

Received 8 September 2020 Revised 11 November 2020 Accepted 13 December 2020

Check for updates

(C) Author(s) (or their employer(s)) 2021. Re-use permitted under CC BY-NC. No commercial re-use. See rights and permissions. Published by BMJ.

For numbered affiliations see end of article.

Correspondence to Dr John A Dodson; John. Dodson@nyumc.org

\section{ABSTRACT}

Objective To develop a 180-day readmission risk model for older adults with acute myocardial infarction (AMI) that considered a broad range of clinical, demographic and age-related functional domains.

Methods We used data from ComprehenSIVe Evaluation of Risk in Older Adults with AMI (SILVER-AMI), a prospective cohort study that enrolled participants aged $\geq 75$ years with AMl from 94 US hospitals. Participants underwent an in-hospital assessment of functional impairments, including cognition, vision, hearing and mobility. Clinical variables previously shown to be associated with readmission risk were also evaluated. The outcome was 180-day readmission. From an initial list of 72 variables, we used backward selection and Bayesian model averaging to derive a risk model $(\mathrm{N}=2004)$ that was subsequently internally validated $(\mathrm{N}=1002)$.

Results Of the 3006 SILVER-AMI participants discharged alive, mean age was 81.5 years, $44.4 \%$ were women and $10.5 \%$ were non-white. Within 180 days, 1222 participants $(40.7 \%)$ were readmitted. The final risk model included 10 variables: history of chronic obstructive pulmonary disease, history of heart failure, initial heart rate, first diastolic blood pressure, ischaemic ECG changes, initial haemoglobin, ejection fraction, length of stay, self-reported health status and functional mobility. Model discrimination was moderate ( 0.68 derivation cohort, 0.65 validation cohort), with good calibration. The predicted readmission rate (derivation cohort) was $23.0 \%$ in the lowest quintile and $65.4 \%$ in the highest quintile.

Conclusions Over $40 \%$ of participants in our sample experienced hospital readmission within 180 days of AMI. Our final readmission risk model included a broad range of characteristics, including functional mobility and self-reported health status, neither of which have been previously considered in 180-day risk models.

\section{INTRODUCTION}

Over the past decade, healthcare systems in the USA and Europe have put considerable resources into understanding and preventing 30-day readmissions among older adults. ${ }^{12}$ Financial concerns have driven much of these efforts: in the USA, hospitals face financial penalties for excessive 30-day readmission

\section{Key questions}

What is already known about this subject?

- For older adults, hospital readmission risk after acute myocardial infarction (AMI) extends beyond the 30-day window traditionally set by payors. Readmission at 180 days more fully encompasses the heightened state of vulnerability after discharge.

What does this study add?

- We considered a broad range of clinical characteristics and functional impairments among patients aged $\geq 75$ years hospitalised with AMI, and 10 were retained in a risk model for readmission at 180 days. Two of these (functional mobility and self-reported health status) are not usually collected in routine care.

How might this impact on clinical practice?

- Our risk model can be used at the point of care to identify older adults at increased readmission risk within 180 days, although our model discrimination was only moderate, indicating that other factors also contribute to risk.

rates in several conditions including acute myocardial infarction (AMI). ${ }^{1}$ While 30 -day readmission events are important from a cost and patient perspective, the period of heighted vulnerability to adverse events (termed the 'post hospital syndrome') ${ }^{3}$ extends beyond this payor-set benchmark. For example, a prior study of Medicare beneficiaries hospitalised for AMI demonstrated that readmission risk remained elevated for several months following discharge. ${ }^{4}$ In light of this phenomenon, considering a longer time horizon of 180 days after discharge may better reflect the vulnerabilities faced by older adults after hospitalisation for AMI.

Despite their relevance for patients, caregivers and health systems, determinants of 180-day readmissions after AMI remain largely unknown. While age alone appears to confer readmission risk beyond 30 days, ${ }^{5}$ 
impairments in functional domains that are increasingly prevalent with advanced age, including cognition, vision, hearing and muscle strength, may also heighten the likelihood of readmission through mechanisms such as increased difficulty comprehending care instructions, delayed recognition of symptoms and increased fall risk. While our own group, ${ }^{6}$ and other investigators, ${ }^{7}$ have demonstrated that these age-associated functional impairments influence 30-day readmission, they have not yet been evaluated in the setting of 180-day readmissions.

In this context, our aim was to develop and validate a 180-day readmission risk model that considered both traditional demographic and clinical variables as well as age-related functional impairments. We used data from the ComprehenSIVe Evaluation of Risk in Older Adults with AMI (SILVER-AMI) study, a prospective multicentre longitudinal study of patients age $\geq 75$ years who were hospitalised with AMI. Participants enrolled in SILVER-AMI underwent a detailed assessment of agerelated functional impairments at the time of hospitalisation. In parallel, detailed clinical information (including variables from prior AMI risk models) was collected. Results from this study can be used to inform prognosis and the design of interventions for older patients at highest risk of 180-day readmission.

\section{METHODS \\ Study participants}

The design of SILVER-AMI has been described previously. ${ }^{8}$ Briefly, patients age $\geq 75$ years were enrolled if they met criteria for the Third Universal Definition of AMI, ${ }^{9}$ as verified by physician investigators at the Yale Coordinating Center. Patients underwent a baseline assessment (in-hospital), including demographics, prehospital symptoms, health status measures (SF-12, Seattle Angina Questionnaire) and a comprehensive functional assessment. Medical records were also provided to the Yale Coordinating Center, where two physicians reviewed AMI eligibility criteria and readmission events, and a research nurse obtained information about medications, cardiac procedures and other details of the hospitalisation. All SILVER-AMI enrolment sites obtained institutional review board approval, and all participants provided written informed consent. While patients were not involved in all stages of study planning, the design of SILVER-AMI was presented to Community Advisory Board directed by the Yale Program on Aging, which is comprised of 8-10 older adult volunteers residing in the New Haven area who meet quarterly to provide feedback about best practices for making the research relevant and impactful to the older adult community.

From 1 November 2013 to 28 October 2016, 3041 participants were enrolled at 94 US study sites/hospitals, with the last follow-up assessment completed on 14 June 2017. The majority of sites were non-academic hospitals $(71 \%)$, and $53 \%$ were located in suburban or rural areas. For purposes of our study, which modelled readmission risk at 180 days, we excluded participants who died in-hospital $(n=35)$, leaving an analytic sample of 3006 participants. We randomly selected 2004 for the derivation cohort, and 1002 for the validation cohort. This allocation of the overall sample allowed sufficient power to derive and validate the risk prediction model.

\section{Outcome}

A primary outcome of the SILVER-AMI study was allcause readmission within 180 days of hospital discharge, which included any overnight hospital stay. Readmissions were identified through a two-step process. During enrolment, the participant identified the hospitals they used for medical care and signed the appropriate medical release forms. When the 180-day follow-up window closed, the research coordinator contacted hospitals that were identified at enrolment to assess and collect readmission records. Separately, participants also reported hospital readmissions to the Yale Coordinating Center. The Yale Coordinating Center then reconciled the hospital records collected by the coordinator against self-reported events to ensure that no readmissions were missing. Readmissions (occurrence and causes) were double-adjudicated by physician investigators at the Yale Coordinating Center. For the purpose of this analysis, we included readmission as a dichotomous variable and did not include subsequent readmissions. Mortality was ascertained through medical record review as well as through interviews with family members, with verification by death certificates, hospital records or obituaries.

\section{Selection of predictors}

For development of our 180-day risk model, we initially selected 72 candidate variables (online supplemental appendix eTable 1) based on: (1) elements from existing AMI readmission risk models, ${ }^{10-13}$ (2) major functional impairments plausibly related to readmission, including cognitive, sensory and physical function and (3) other clinical variables that, per the clinical judgement of the study investigators, may potentially influence readmission (such as symptom burden, self-reported health status and in-hospital complications). The following functional domains were considered: general cognitive function (Telephone Interview for Cognitive Status), ${ }_{15}^{14}$ verbal fluency (Controlled Word Association Task), ${ }^{15}$ vision impairment (Visual Functioning Questionnaire), ${ }^{16}$ hearing impairment (global question about impairments imposed by hearing), ${ }^{17}$ poor nutrition (4.5 kg weight loss in prior year), activities of daily living disability, ${ }^{18}$ depressive symptoms (Patient Health Questionnaire 8), ${ }^{19}$ upper extremity strength (handheld dynamometer, B\&L Engineering, Santa Ana, California, USA), ${ }^{20}$ fall history and functional Timed Up and Go (TUG), ${ }^{21}$ which involved evaluation of chair rise and gait speed over a distance of $3 \mathrm{~m}$ (online supplemental appendix eTable 2). When possible, we selected cutpoints for all functional impairments based on previously validated thresholds ${ }^{14-17}{ }^{19}$; 
if there was ambiguity, a consensus was reached among study team members based on the best available evidence.

\section{Statistical analysis}

We generated descriptive statistics in the overall cohort, using means for continuous variables and percentages for categorical variables. For categorical variables, we chose thresholds based on clinical relevance and distributions. From our initial list, we omitted variables with $>20 \%$ missingness and those with extremely low $(<5 \%)$ or high $(>95 \%)$ prevalence. Under the assumption that data were missing at random, we multiply imputed the data 20 times. Per recommendations of White $e t a l,{ }^{22}$ we reduced the number of candidate variables by applying multivariable logistic regression with backward selection to an aggregate dataset of the 20 imputations, retaining the 30 variables with the strongest adjusted associations with the outcome. We then applied Bayesian model averaging with multivariable logistic regression to these final candidates in each of the multiply imputed datasets. ${ }^{23}$ The final predictors were those exhibiting a positive posterior probability in at least half of the imputations. These predictors were subsequently examined for linearity and used in a multivariable model fit to each imputation using generalised estimating equations to adjust for the clustering of patients within hospitals. The final coefficients were calculated using Rubin's rules. ${ }^{24}$ Because Bayesian model averaging was used to select variables rather than the corresponding $\mathrm{p}$ values, some model terms may not exhibit $\mathrm{p}$ values below $0.05 .^{25}$ In order to compare the relative weight of predictors with different incremental change per unit (eg, linear vs categorical), we generated standardised beta coefficients whereby the mean of each variable equaled zero and the SD of each variable equaled 1.0.

Discrimination and calibration of the final model were respectively evaluated in both derivation and validation cohorts with the C-statistic and the Hosmer-Lemeshow goodness of fit statistic. Observed and predicted probabilities of the outcome were calculated for quintiles of the risk score obtained by applying the final model to the validation data.

Because of the potential for the competing risk of death to bias our study results, we performed sensitivity analyses to account for the 62 (3\%) SILVER-AMI participants in the derivation cohort who died without being readmitted. ${ }^{26}$ Specifically, we ran our analyses again after imputing the readmission outcome under the following three assumptions for these 62 individuals: (1) all were readmitted; (2) none were readmitted; and (3) readmitted based on missing at random. In order to evaluate robustness of our study results to the competing risk of death, we compared the CIs from these three assumptions with those from our primary analysis (which did not account for competing risk of death).

Analyses were performed in SAS V9.4, with the exception of the Bayesian model averaging, which used the $\mathrm{R}$ package named BMA. For bedside prognostication, we then developed a web-based calculator derived from model effect estimates.

\section{RESULTS}

\section{Baseline characteristics}

The mean age of the study sample was 81.5 years; $44.4 \%$ of participants were women, and $10.5 \%$ were of non-white race. Slightly over one-quarter of the sample (26.3\%) presented with ST elevation myocardial infarction. Over half $(53.4 \%)$ had a known history of coronary artery disease, and $40.6 \%$ had undergone previous coronary revascularisation. Functional impairments were observed most commonly in mobility (TUG $\geq 15 \mathrm{~s}$ or unable to complete TUG) (71.2\%), weak grip strength $(60.1 \%)$, unintentional weight loss $(21.9 \%)$ and multiple falls within the prior year $(19.7 \%)$. The majority of participants $(59.0 \%)$ experienced at least one in-hospital complication (which included bleeding, acute kidney injury, decompensated heart failure, arrhythmia or hyperglycaemic).

\section{Readmission at $\mathbf{1 8 0}$ days}

Within 180 days of discharge, 1222 unique participants ( $40.7 \%$ of study sample) experienced at least one hospital readmission. Overall, there were 2016 readmissions: 742 participants were readmitted once, 298 were readmitted twice and 182 were readmitted three or more times. The majority of readmissions $(61.0 \%)$ were cardiac related (table 1). The most common cause of readmission was congestive heart failure $(17.7 \%)$, followed by non-ST-elevated myocardial infarction $(8.4 \%)$, elective procedure $(7.0 \%)$ and arrhythmia $(6.1 \%)$. There were 266 deaths $(8.8 \%$ of study sample) within the same observation period.

In bivariate analyses, compared with participants who were not readmitted, those who were readmitted were of relatively similar age ( 81.7 vs 81.4 years, $\mathrm{p}=0.097)$ and sex (per cent male $53.8 \%$ vs $56.8 \%, \mathrm{p}=0.112$ ) but more likely to be non-white $(12.0 \%$ vs $9.5 \%, \mathrm{p}=0.035)$ and less likely to be married or living with a partner $(47.2 \%$ vs $52.5 \%$, $\mathrm{p}=0.004$ ). Medical comorbidities were generally higher among readmitted participants (table 2). Participants who were readmitted also had more functional impairments including cognitive impairment $(21.4 \%$ vs $16.5 \%$, $\mathrm{p}<0.001)$, vision impairment $(9.9 \%$ vs $7.6 \%, \mathrm{p}=0.024)$, unintentional weight loss $(25.0 \%$ vs $20.5 \%, \mathrm{p}=0.003)$, multiple prior falls $(23.6 \%$ vs $17.0 \%, \mathrm{p}<0.001)$ and impaired functional mobility ( $78.5 \%$ vs $66.3 \%, \mathrm{p}<0.001)$.

\section{Multivariable results}

After application of Bayesian model averaging to the derivation cohort, 10 variables were retained in the final prediction model: history of chronic obstructive pulmonary disease (COPD), history of heart failure, initial heart rate, first diastolic BP, ischaemic ECG changes, initial haemoglobin, ejection fraction, length of stay, selfreported health status and functional mobility (figure 1). The strongest predictors based on standardised beta 


\begin{tabular}{|c|c|}
\hline & $\begin{array}{l}\text { Total } \\
\text { (N=2016) (\%) }\end{array}$ \\
\hline Cardiovascular & $1183(58.7)$ \\
\hline Congestive heart failure (CHF) & $357(17.7)$ \\
\hline Non-ST-elevated myocardial infarction (NSTEMI) & $169(8.4)$ \\
\hline Elective procedure & $142(7.0)$ \\
\hline Arrhythmia & $123(6.1)$ \\
\hline Non-cardiac chest pain & $119(5.9)$ \\
\hline Unstable angina & $103(5.1)$ \\
\hline Stroke & $37(1.8)$ \\
\hline Other cardiovascular including hypertensive disease & $26(1.3)$ \\
\hline $\begin{array}{l}\text { Peripheral vascular disease, including aorta, carotids and } \\
\text { extremities }\end{array}$ & $25(1.2)$ \\
\hline Valvular heart disease & $22(1.1)$ \\
\hline ST-elevated myocardial infarction (STEMI) & $20(1.0)$ \\
\hline Thrombotic event & $15(0.7)$ \\
\hline Cardiac syncope & $13(0.6)$ \\
\hline Transient ischaemic attack & $11(0.6)$ \\
\hline Non-cardiovascular & $833(41.3)$ \\
\hline Bleeding episode & $183(9.1)$ \\
\hline Other non-cardiovascular & $168(8.3)$ \\
\hline Pneumonia including aspiration pneumonitis & $68(3.4)$ \\
\hline Sepsis/septic shock & $60(3.0)$ \\
\hline Fall/fracture & $58(2.9)$ \\
\hline $\begin{array}{l}\text { Renal disorders (renal failure, electrolyte and acid-base } \\
\text { abnormalities) }\end{array}$ & $45(2.2)$ \\
\hline COPD/asthma & $41(2.0)$ \\
\hline Urinary tract infection and urinary system complaints & $36(1.8)$ \\
\hline Skin and soft tissue infections & $32(1.6)$ \\
\hline Pleural effusion/pneumothorax & $24(1.2)$ \\
\hline Diabetes, including blood glucose abnormalities & $19(0.9)$ \\
\hline Dehydration & $19(0.9)$ \\
\hline Weakness/fatigue/failure to thrive & $19(0.9)$ \\
\hline Syncope & $17(0.8)$ \\
\hline $\begin{array}{l}\text { Other lung disorders including acute, congenital and } \\
\text { unspecified lung abnormalities }\end{array}$ & $11(0.6)$ \\
\hline Vomiting & $11(0.6)$ \\
\hline Clostridium difficile-associated infection & $9(0.5)$ \\
\hline Primary cancer of trachea, bronchus, lung and pleura & $8(0.4)$ \\
\hline Psychiatric & $4(0.2)$ \\
\hline Fibrosis of lung and other chronic lung disorders & $1(0.1)$ \\
\hline
\end{tabular}

Table describes all readmissions among study sample; 1222 unique participants experienced readmission (742 readmitted once, 298 readmitted twice and 182 readmitted $\geq 3$ times).

COPD, chronic obstructive pulmonary disease.

coefficients were history of heart failure (OR 1.85, 95\% CI 1.46 to 2.34 ; standardised beta $=5.10)$, initial haemoglobin (OR 0.90 per $\mathrm{g} / \mathrm{dL}$ unit increase, $95 \%$ CI 0.86 to 0.94 , standardised beta $=4.22)$ and self-reported health status (OR 1.17 per level worsening, 95\% CI 1.07 to 1.29 , standardised beta $=3.30$ ). Discrimination of this model was moderate (C statistic $0.68995 \%$ CI 0.675 to 0.685 ) derivation cohort, 0.65 (95\% CI 0.638 to 0.654 ) validation cohort). The model demonstrated good calibration evidenced by $\mathrm{p}$ values $>0.05$ for the Hosmer-Lemeshow statistic across all multiply imputed datasets.

Figure 2 plots the means and CIs of the observed probabilities of readmission versus those predicted for the validation cohort for quintiles of the risk scores based on the coefficients of the model developed in the derivation cohort. The predicted readmission rate (derivation cohort) was $23.0 \%$ in the lowest quintile and $65.4 \%$ in the highest quintile of risk (full range of predicted risk: $14.3 \%-91.4 \%$ ). The beta coefficients from the final regression equation are presented in online supplemental appendix eTable 3 .

\section{Sensitivity analyses}

Under the assumptions that among participants who died before readmission, (1) all were readmitted, (2) none were readmitted or (3) readmitted based on missing at random, there were negligible changes in effect estimates. For example, for COPD, the OR assuming all were readmitted was 1.46 (95\% CI 1.12 to 1.91 ); assuming none were readmitted, the OR was 1.54 (95\% CI 1.16 to 2.04); and assuming readmission data were missing at random, the OR was 1.51 (95\% CI 1.15 to 2.00). Full findings for these scenarios are shown in the online supplemental appendix eTable 4.

\section{DISCUSSION}

To our knowledge, we developed the first 180-day readmission risk model for older adults after hospitalisation for AMI. Our study had several important findings. First, over $40 \%$ of participants were readmitted at least once within 6 months; while heart failure was the most common cause, it accounted for fewer than one in five hospitalisations, underscoring the broad range of acute medical conditions (cardiac and non-cardiac) leading to readmissions. Second, participants who were readmitted had a greater burden of functional impairments, including cognitive impairment, vision impairment, unintentional weight loss, multiple prior falls and impaired functional mobility, although only functional mobility was retained in the final risk model. Third, our final risk model included a broad range of factors related to presentation characteristics (eg, ischaemic ECG changes and initial heart rate), medical history (prior heart failure and COPD), diagnostic testing (ejection fraction and haemoglobin), functional mobility and self-reported health status. Two of these factors (functional mobility and self-reported health status) are not typically collected in current practice but, among the 72 variables we considered, were among the final predictors.

We previously published a risk model for 30-day readmission in the same cohort, which was developed based on 547 participants readmitted within that timeframe. ${ }^{6}$ Our 30-day risk model had moderate discrimination (C 
Coronary artery disease

Table 2 Participant characteristics: readmitted versus not readmitted at 180 days ( $N=3006)$

\begin{tabular}{|c|c|c|c|}
\hline & $\begin{array}{l}\text { 180-day readmission } \\
(\mathrm{N}=1222) \\
\text { Mean (SD) or } \mathrm{N}(\%)\end{array}$ & $\begin{array}{l}\text { No } 180 \text {-day readmission } \\
(\mathrm{N}=1784) \\
\text { Mean (SD) or } \mathrm{N}(\%)\end{array}$ & $P$ value \\
\hline \multicolumn{4}{|l|}{ Demographics } \\
\hline Male sex & $658(53.8)$ & $1013(56.8)$ & 0.112 \\
\hline Non-white race & $147(12.0)$ & $170(9.5)$ & 0.035 \\
\hline \multicolumn{4}{|l|}{ Medical history } \\
\hline Hypertension & $1082(88.5)$ & $1484(83.2)$ & $<0.001$ \\
\hline Dyslipidaemia & $789(64.6)$ & $1109(62.2)$ & 0.180 \\
\hline Arrhythmia & $370(30.3)$ & $379(21.2)$ & $<0.001$ \\
\hline Heart failure & $330(27.0)$ & $233(13.1)$ & $<0.001$ \\
\hline Valvular disease & $194(15.9)$ & $155(8.7)$ & $<0.001$ \\
\hline Stroke & $234(19.1)$ & $234(13.1)$ & $<0.001$ \\
\hline Diabetes mellitus & $515(42.1)$ & $601(33.7)$ & $<0.001$ \\
\hline COPD & $221(18.1)$ & 205 (11.5) & $<0.001$ \\
\hline Current or ever smoker & $693(56.7)$ & $973(54.5)$ & 0.217 \\
\hline \multicolumn{4}{|l|}{ Presentation characteristics } \\
\hline STEMI & $285(23.3)$ & $506(28.4)$ & 0.002 \\
\hline Chest pain as primary symptom & $493(40.3)$ & $718(40.2)$ & 0.913 \\
\hline$\geq 6$ hours from symptoms to presentation & $562(46.0)$ & $709(39.7)$ & $<0.001$ \\
\hline Initial WCC count, mean (SD) & $10.1(6.23)$ & $9.3(3.78)$ & $<0.001$ \\
\hline eGFR, mean (SD) & $51.7(20.65)$ & $56.6(19.23)$ & $<0.001$ \\
\hline TIMI score (NSTEMI), mean (SD) & $4.7(1.19)$ & $4.6(1.18)$ & 0.058 \\
\hline TIMI score (STEMI), mean (SD) & $6.5(1.87)$ & $5.9(1.42)$ & $<0.001$ \\
\hline GRACE ACS score, mean (SD) & $150.5(23.21)$ & $142.0(21.39)$ & $<0.001$ \\
\hline \multicolumn{4}{|c|}{ In-hospital diagnostics, therapies and complications } \\
\hline Left ventricular ejection fraction & & & $<0.001$ \\
\hline Normal ( $\geq 50 \%)$ & $542(44.4)$ & $985(55.2)$ & \\
\hline Mildly reduced (40\%-50\%) & $247(20.2)$ & $350(19.6)$ & \\
\hline Moderately reduced $(30 \%-40 \%)$ & $187(15.3)$ & $206(11.5)$ & \\
\hline Severely reduced $(<30 \%)$ & $116(9.5)$ & $96(5.4)$ & \\
\hline \multicolumn{4}{|l|}{ Medications within first 24 hours } \\
\hline Aspirin & $1160(94.9)$ & $1716(96.2)$ & 0.116 \\
\hline Antiplatelet agent (P2Y12 inhibitor) & $719(58.8)$ & $1154(64.7)$ & 0.001 \\
\hline Beta blocker & $945(77.3)$ & $1420(79.6)$ & 0.148 \\
\hline Intravenous antithrombotic agent & & & 0.035 \\
\hline No agent & $234(19.1)$ & $281(15.8)$ & \\
\hline Single agent (heparin or bivalirudin) & $878(71.8)$ & $1320(74.0)$ & \\
\hline
\end{tabular}


Table 2 Continued

\begin{tabular}{|c|c|c|c|}
\hline & $\begin{array}{l}\text { 180-day readmission } \\
(\mathrm{N}=1222) \\
\text { Mean (SD) or } \mathrm{N}(\%)\end{array}$ & $\begin{array}{l}\text { No } 180 \text {-day readmission } \\
(\mathrm{N}=1784) \\
\text { Mean (SD) or } \mathrm{N}(\%)\end{array}$ & $P$ value \\
\hline Two agents (heparin or bivalirudin plus GP IIb/IIla & $109(8.9)$ & $183(10.3)$ & \\
\hline Revascularisation status & & & $<0.001$ \\
\hline No cardiac catheterisation & $229(18.7)$ & $229(12.8)$ & \\
\hline Cardiac catheterisation only & $229(18.7)$ & $265(14.9)$ & \\
\hline Cardiac catheterisation with $\mathrm{PCl}$ & $633(51.8)$ & $1067(59.8)$ & \\
\hline Coronary artery bypass graft surgery & $131(10.7)$ & $223(12.5)$ & \\
\hline In-hospital complication: bleeding & $337(27.6)$ & $436(24.4)$ & 0.053 \\
\hline In-hospital complication: acute kidney injury & $349(28.6)$ & $343(19.2)$ & $<0.001$ \\
\hline In-hospital complication: heart failure & $219(17.9)$ & $195(10.9)$ & $<0.001$ \\
\hline \multicolumn{4}{|l|}{ Functional impairments } \\
\hline Cognitive impairment (TICS) & & & $<0.001$ \\
\hline No impairment (TICS $\geq 27$ ) & $961(78.6)$ & $1490(83.5)$ & \\
\hline Mild impairment (TICS 23-36) & $147(12.0)$ & $167(9.4)$ & \\
\hline Moderate or severe impairment (TICS $\leq 22$ ) & $96(7.9)$ & $96(5.4)$ & \\
\hline Verbal fluency (total COWAT S words), mean (SD) & $9.3(4.74)$ & $9.9(4.78)$ & $<0.001$ \\
\hline Clinically significant vision impairment (VFQ-25) & $121(9.9)$ & $135(7.6)$ & 0.024 \\
\hline Clinically significant hearing impairment & $155(12.7)$ & $249(14.0)$ & 0.291 \\
\hline Unintentional weight loss (>10 lbs. in 1 year) & $305(25.0)$ & $366(20.5)$ & 0.003 \\
\hline ADL disability (any) & $198(16.2)$ & $214(12.0)$ & 0.001 \\
\hline Multiple falls (>1 within past year) & $289(23.6)$ & $304(17.0)$ & $<0.001$ \\
\hline Weak grip strength & $781(63.9)$ & $1026(57.5)$ & $<0.001$ \\
\hline Functional mobility (based on Timed Up and Go) & & & $<0.001$ \\
\hline Completed in $\leq 15 \mathrm{~s}$ & $263(21.5)$ & $602(33.7)$ & \\
\hline Completed in $>15$ and $\leq 25 \mathrm{~s}$ & $233(19.1)$ & $386(21.6)$ & \\
\hline Completed in $>25 \mathrm{~s}$ & $223(18.2)$ & $260(14.6)$ & \\
\hline Unable to complete & $290(23.7)$ & $270(15.1)$ & \\
\hline \multicolumn{4}{|l|}{ Other measures } \\
\hline Short-Form 12: general health question (four categories) & & & $<0.001$ \\
\hline Excellent or very good & $286(23.4)$ & $556(31.2)$ & \\
\hline Good & $414(33.9)$ & $692(38.8)$ & \\
\hline Fair & 357 (29.2) & 403 (22.6) & \\
\hline Poor & $161(13.2)$ & $131(7.3)$ & \\
\hline Depressive symptoms (PHQ-8 $\geq 10$ ) & 222 (18.2) & $200(11.2)$ & $<0.001$ \\
\hline
\end{tabular}

For descriptive purposes, 'impaired functional mobility' defined as Timed Up and Go $>15 \mathrm{~s}$ or unable to complete test.

Data missing for fewer than $5 \%$ of variables except for left ventricular ejection fraction (9.2\%) and Timed Up and Go (15.9\%).

$\mathrm{ADL}$, activities of daily living; BP, blood pressure; COPD, chronic obstructive pulmonary disease; COPD, chronic obstructive pulmonary disease; COWAT, Controlled Oral Word Association Test; eGFR, estimated glomerular filtration rate; NSTEMI, non-ST-elevation myocardial infarction; PCI, percutaneous coronary intervention; PHQ-8, Patient Health Questionnaire 8; STEMI, ST-elevation myocardial infarction; TICS, Telephone Interview for Cognitive Status; TIMI, thrombolysis in myocardial infarction; VFQ-25, Visual Function Questionnaire 25; WCC, white cell count.

statistic: 0.65 derivation cohort, 0.63 validation cohort), was well calibrated and included functional mobility, ejection fraction, COPD, arrhythmia, acute kidney injury, first diastolic blood pressure, P2Y12 inhibitor use and selfreported health status. In the current study, we focused on 180-day readmissions given that mechanistically, posthospital risk among older adults extends beyond the 30-day benchmark commonly set by payors. For example, Dharmarajan $e t a l{ }^{4}$ using a sample of over 500000 Medicare beneficiaries hospitalised with AMI, demonstrated that even 90 days after AMI, the risk for hospital admission was six times greater than among the general older adult population. These findings suggest there is a prolonged period of posthospital risk before restoration of homeostasis. Factors related to hospitalisation such as immobility, poor nutrition or iatrogenic events may contribute to these phenomena. ${ }^{327}$ Compared with our 30-day risk model, we found 180-day risk factors that were unique 


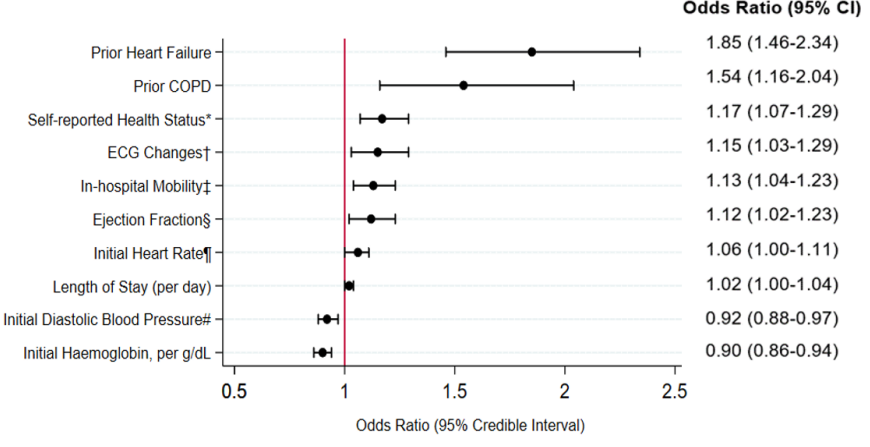

Figure 1 Risk model elements: 180-day readmission. After Bayesian model averaging with multivariable logistic regression, 10 variables were retained in the final risk model: these included comorbidities, presentation characteristics, self-reported health status and functional mobility. *Based on Short-Form 12 general health: excellent or very good (reference), good, fair and poor. †ECG changes: no ischaemic changes (reference), ST depression or T-wave inversion, ST elevation. $\ddagger$ Timed Up and Go scores: $\leq 15 \mathrm{~s}$ (reference), $>15-\leq 25 \mathrm{~s},>25 \mathrm{~s}$, unable to complete. §Ejection fraction categories $\geq 50$ (reference), $40-<50,30-<40$ and $<30$. ๆHeart rate categories: $<50$ (reference), 50-69, 70-79, 80-89, 90-99, 100-109, 110-129, 130-149 and $\geq 150 \mathrm{bpm}$. \#Diastolic blood pressure categories: $<50$ (reference), 50-59, 60-69, $70-79,80-89,90-99$ and $\geq 100$. COPD, chronic obstructive pulmonary disease.

(initial heart rate, ischaemic ECG changes, initial haemoglobin, prior heart failure and length of stay), while others were common across both time periods (initial diastolic $\mathrm{BP}$, ejection fraction, prior COPD, functional mobility and self-reported health status). In practice, our 30-day and 180-day readmission models may be used in conjunction to provide short-term and intermediate-term prognostication

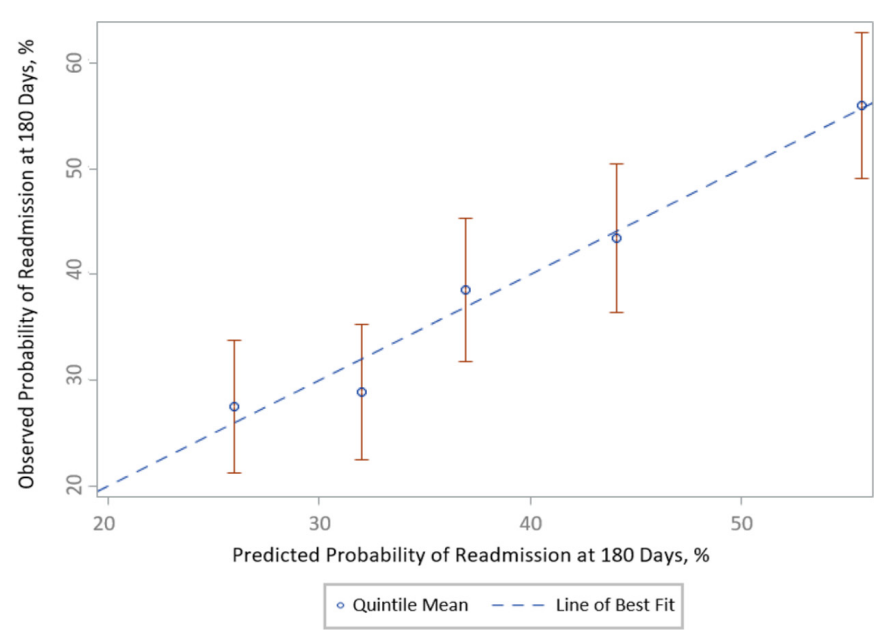

Figure 2 Calibration of predicted versus observed probability of readmission at 180-days in the SILVER-AMI validation cohort, by quintile. Model calibration, validation cohort (by quintile). Shown are observed versus predicted 180-day readmission rates, by quintile, within the validation cohort. Error bars (red) represent 95\% Cls. Among these quintiles, the SILVER-AMI readmission risk model was well calibrated (Hosmer-Lemeshow $p>0.05$ ). SILVER-AMI, ComprehenSIVe Evaluation of Risk in Older Adults with AMI. for patients, family members, clinicians and health systems. While 30-day readmission risk may be more relevant for immediate care planning, 180-day risk is more relevant for ongoing outpatient management. Notably, functional mobility and health status served as robust indicators that were relevant across both time periods of risk, which argues for their measurement in the routine care of older adults. Prior studies in other AMI cohorts have found that both mobility and health status measures predict outcomes ranging from cardiovascular events ${ }^{28}$ to hospital readmission $^{29}$ and survival, ${ }^{29}$ although their measurement remains largely outside routine clinical practice.

Our initial pool of variables included those found in prior AMI readmission risk models, major functional impairments plausibly related to readmission and other variables based on clinical judgement that may potentially have influenced readmission. Despite this thorough selection process, as well as the broad range of care environments in SILVER-AMI, our model had only modest discrimination. We reported similar findings in our 30-day readmission model, ${ }^{6}$ which we believe underscores that other factors, such as those relating to the community or health system, may be important elements of readmission risk. In addition, while we captured in-hospital complications, our dataset did not include other events in the hospital (eg, delirium, inadequate nutrition and prolonged immobility) that are more difficult to quantify but may also contribute to readmission risk. ${ }^{3430}$ Notably, a recent study by Rawal $e t a \ell^{30}$ of 207 medical inpatients found that those reporting disturbances in multiple domains of sleep, mobility, nutrition and mood were significantly more likely to be readmitted within 30 days than those reporting little or no disturbance, even after adjustment for age, sex, comorbidity burden, laboratory abnormalities and length of stay. To our knowledge, similar data have not been published for 180-day readmission, and further study is therefore needed to evaluate whether the hospital environment affects outcomes within this timeframe.

Mechanistically, we believe there are plausible explanations for the factors we found to be associated with readmission. For example, history of heart failure was the strongest independent predictor of 180-day readmission, and multiple studies have demonstrated that older adults with heart failure are prone to hospital readmissions both for cardiac-specific issues (eg, haemodynamic decompensation) and an array of non-cardiac causes. ${ }^{131}$ Impaired functional mobility was another independent predictor of 180-day readmission in our model and is a composite measure that encompasses balance and gait manoeuvres used on a daily basis; it has considerable overlap with the frailty syndrome. ${ }^{32}$ Participants with impaired functional mobility may have been at risk from both the stresses of inpatient hospitalisation as well as impaired recovery after discharge, placing them at heightened risk for readmission.

There are several limitations to our study that warrant consideration. First, while SILVER-AMI made an effort 
to be broadly inclusive of hospitalised older adults, the recruitment process excluded those with severe cognitive impairment or delirium at presentation with no proxy available, given the requirement for completion of detailed study instruments. Therefore, while severe cognitive impairment may be an independent determinant of readmission in older adults, ${ }^{33}$ it was not well represented in our dataset. Second, our risk model was based on first readmission and did not take multiple readmissions into account. Time to first event is the convention for most readmission risk models to avoid disproportionately weighing individuals with frequent readmissions. Third, while our model was internally validated, the model may perform differently in external datasets. To our knowledge, no such dataset for validation yet exists, but this remains a worthy exercise for future investigations.

In conclusion, among patients age $\geq 75$ years hospitalised for AMI, we developed and internally validated a risk model for 180-day hospital readmission that considered a broad range of functional impairments, comorbidities and presentation characteristics. Two variables (impaired functional mobility and poor self-reported health status) not captured in most prior cohort studies were retained in the final risk model, along with more traditional clinical characteristics. Collection of functional mobility and health status can help to better determine postdischarge risk. However, while our model was well calibrated, it had only modest discrimination, suggesting that 180-day readmissions are also influenced by other factors: either related to the physiological stresses of hospitalisation (eg, sleep disruption) or community-level or health systemlevel factors (eg, timely access to outpatient care) that influence postdischarge outcomes.

\section{Author affiliations}

${ }^{1}$ Leon H. Charney Division of Cardiology, Department of Medicine, New York University School of Medicine, New York, New York, USA

${ }^{2}$ Division of Healthcare Delivery Science, Department of Population Health, New York University School of Medicine, New York, New York, USA

${ }^{3}$ Geriatrics Section, Department of Internal Medicine, Yale School of Medicine, New Haven, Connecticut, USA

${ }^{4}$ Center for Outcomes Research and Evaluation, Yale-New Haven Hospital, New Haven, Connecticut, USA

${ }^{5}$ Section of Cardiovascular Medicine, Department of Internal Medicine, Yale University, New Haven, Connecticut, USA

${ }^{6}$ Robert Wood Johnson Foundation Clinical Scholars Program, Department of Internal Medicine, Yale School of Medicine, New Haven, Connecticut, USA ${ }^{7}$ Department of Health Policy and Management, Yale School of Public Health, New Haven, Connecticut, USA

${ }^{8}$ Duke Clinical Research Institute, Durham, North Carolina, USA

${ }^{9}$ International Heart Institute of Montana, Missoula, Montana, USA

${ }^{10}$ Section of General Internal Medicine, Department of Internal Medicine, Yale School of Medicine, New Haven, Connecticut, USA

Contributors JD: planning, article writing and submission; AH: planning, statistical check and article writing; TM: statistical analysis and article writing; MG: conducting, patient enrolment, data collection and reporting; HK: planning and article check; ST: data collection and reporting, and data check; MN and GO: article check; MT: planning and article check; DS: patient enrolment and article check; TMG: planning and article writing; SIC: principal investigator, planning, conducting and article writing.

Funding This research was supported by the National Heart, Lung, And Blood Institute of the National Institutes of Health (R01HL115295). This work was conducted at the Yale Program on Aging/Claude D. Pepper Older Americans Independence Center (P30AG21342). The project described used REDCap, which is supported by the National Center for Advancing Translational Sciences, National Institutes of Health $(\mathrm{NIH})$, through grant UL1 TR00000. JD is supported by a Patient Oriented Career Development Award (K23 AG052463) from the National Institute of Aging. AH was supported by NIA training grant T32 AG019134. TMG is the recipient of an Academic Leadership Award (K07AG043587) from the National Institute on Aging MN is supported by an NIH training grant T32HL069749-15.

Disclaimer The content is solely the responsibility of the authors and does not necessarily represent the official views of the National Institutes of Health.

Competing interests SIC receives funding for her work as a reviewer for the CVS Caremark Clinical Pharmacy Program for the state of Connecticut.

Patient consent for publication Not required.

Ethics approval All ComprehenSIVe Evaluation of Risk in Older Adults with AMI enrolment sites obtained support from their local Institutional Review Boards.

Provenance and peer review Not commissioned; externally peer reviewed.

Data availability statement Data are available on reasonable request. Interested researchers can contact the senior author (SIC) for further information.

Open access This is an open access article distributed in accordance with the Creative Commons Attribution Non Commercial (CC BY-NC 4.0) license, which permits others to distribute, remix, adapt, build upon this work non-commercially, and license their derivative works on different terms, provided the original work is properly cited, appropriate credit is given, any changes made indicated, and the use is non-commercial. See: http://creativecommons.org/licenses/by-nc/4.0/.

Correction notice This article has been corrected since it first published. The provenance and peer review statement has been included.

ORCID iD

John A Dodson http://orcid.org/0000-0003-0163-3013

\section{REFERENCES}

1 Dharmarajan K, Hsieh AF, Lin Z, et al. Diagnoses and timing of 30-day readmissions after hospitalization for heart failure, acute myocardial infarction, or pneumonia. JAMA 2013;309:355-63.

2 Blunt I, Bardsley M, Grove A, et al. Classifying emergency 30-day readmissions in England using routine hospital data 2004-2010: what is the scope for reduction? Emerg Med J 2015;32:44-50.

3 Krumholz HM. Post-hospital syndrome--an acquired, transient condition of generalized risk. N Engl J Med 2013;368:100-2.

4 Dharmarajan K, Hsieh AF, Kulkarni VT, et al. Trajectories of risk after hospitalization for heart failure, acute myocardial infarction, or pneumonia: retrospective cohort study. BMJ 2015;350:h411.

5 Dharmarajan K, Hsieh A, Dreyer RP, et al. Relationship between age and trajectories of rehospitalization risk in older adults. J Am Geriatr Soc 2017;65:421-6.

6 Dodson JA, Hajduk AM, Murphy TE, et al. Thirty-day readmission risk model for older adults hospitalized with acute myocardial infarction. Circ Cardiovasc Qual Outcomes 2019;12:e005320.

7 Greysen SR, Stijacic Cenzer I, Auerbach AD, et al. Functional impairment and hospital readmission in Medicare seniors. JAMA Intern Med 2015;175:559-65.

8 Dodson JA, Geda M, Krumholz HM, et al. Design and rationale of the comprehensive evaluation of risk factors in older patients with AMI (SILVER-AMI) study. BMC Health Serv Res 2014;14:506.

9 Thygesen K, Alpert JS, Jaffe AS, et al. Third universal definition of myocardial infarction. Eur Heart J 2012;33:2551-67.

10 Dharmarajan K, Krumholz HM. Strategies to reduce 30-day readmissions in older patients hospitalized with heart failure and acute myocardial infarction. Curr Geriatr Rep 2014;3:306-15.

11 Krumholz HM, Lin Z, Drye EE, et al. An administrative claims measure suitable for profiling Hospital performance based on 30-day all-cause readmission rates among patients with acute myocardial infarction. Circ Cardiovasc Qual Outcomes 2011;4:243-52.

12 Desai MM, Stauffer BD, Feringa $\mathrm{HHH}$, et al. Statistical models and patient predictors of readmission for acute myocardial infarction: a systematic review. Circ Cardiovasc Qual Outcomes 2009;2:500-7.

13 Burke RE, Schnipper JL, Williams MV, et al. The HOSPITAL score predicts potentially preventable 30 -day readmissions in conditions targeted by the hospital readmissions reduction program. Med Care 2017;55:285-90.

14 Brandt J, Spencer M, Folstein M. The telephone interview for cognitive status. Neuropsychiatry Neuropsychol Behav Neurol 1988; $1: 111-7$. 
15 Rodríguez-Aranda C, Martinussen M. Age-related differences in performance of phonemic verbal fluency measured by controlled oral word association task (COWAT): a meta-analytic study. Dev Neuropsychol 2006;30:697-717.

16 Mangione CM, Lee PP, Gutierrez PR, et al. Development of the 25-item National eye Institute visual function questionnaire. Arch Ophthalmol 2001;119:1050.

17 Hayman KJ, Kerse N, Dyall L, et al. Life and living in advanced age: a cohort study in New Zealand--e Puāwaitanga o Nga Tapuwae Kia Ora Tonu, LiLACS NZ: study protocol. BMC Geriatr 2012;12:33.

18 Katz S. Assessing self-maintenance: activities of daily living, mobility, and instrumental activities of daily living. J Am Geriatr Soc 1983;31:721-7.

19 Kroenke K, Strine TW, Spitzer RL, et al. The PHQ-8 as a measure of current depression in the general population. $J$ Affect Disord 2009;114:163-73.

20 Rantanen T, Guralnik JM, Foley D, et al. Midlife hand grip strength as a predictor of old age disability. JAMA 1999;281:558-60.

21 Podsiadlo D, Richardson S. The timed "Up \& Go": a test of basic functional mobility for frail elderly persons. J Am Geriatr Soc 1991;39:142-8.

22 White IR, Royston P, Wood AM. Multiple imputation using chained equations: issues and guidance for practice. Stat Med 2011;30:377-99.

23 Murphy TE, Tsang SW, Leo-Summers LS, et al. Bayesian model averaging for selection of a risk prediction model for death within thirty days of discharge: the SILVER-AMI study. Int J Stat Med Res 2019;8:1-7.
24 Rubin DB. Multiple imputation for nonresponse in surveys Donald B, 2004.

25 Sica GT. Bias in research studies. Radiology 2006;238:780-9.

26 Murphy TE, Gill TM, Leo-Summers LS, et al. The competing risk of death in longitudinal geriatric outcomes. J Am Geriatr Soc 2019;67:357-62.

27 Goldwater DS, Dharmarajan K, McEwan BS, et al. Is posthospital syndrome a result of hospitalization-induced allostatic overload? J Hosp Med 2018;13. doi:10.12788/jhm.2986. [Epub ahead of print: 30 May 2018].

28 Matsuzawa $\mathrm{Y}$, Konishi M, Akiyama E, et al. Association between gait speed as a measure of frailty and risk of cardiovascular events after myocardial infarction. J Am Coll Cardiol 2013;61:1964-72.

29 Soto GE, Jones P, Weintraub WS, et al. Prognostic value of health status in patients with heart failure after acute myocardial infarction. Circulation 2004; 110:546-51.

30 Rawal S, Kwan JL, Razak F, et al. Association of the trauma of hospitalization with 30-day readmission or emergency department visit. JAMA Intern Med 2019;179:38-45.

31 Feltner $\mathrm{C}$, Jones $\mathrm{CD}$, Cené CW, et al. Transitional care interventions to prevent readmissions for persons with heart failure: a systematic review and meta-analysis. Ann Intern Med 2014;160:774.

32 Milte R, Crotty M. Musculoskeletal health, frailty and functional decline. Best Pract Res Clin Rheumatol 2014;28:395-410. doi:10.1016/j.berh.2014.07.005

33 Daiello LA, Gardner R, Epstein-Lubow G, et al. Association of dementia with early rehospitalization among Medicare beneficiaries. Arch Gerontol Geriatr 2014;59:162-8. 


\section{Correction: 180-day readmission risk model for older adults with acute myocardial infarction: the SILVER-AMI study}

Dodson JA, Hajduk AM, MurphyTE, et al. 180-day readmission risk model for older adults with acute myocardial infarction: the SILVER-AMI study. Open Heart 2021;8:e001442. doi:10.1136/openhrt-2020-001442

This article has been corrected since it was first published. The provenance and peer review statement has been included.

Open access This is an open access article distributed in accordance with the Creative Commons Attribution Non Commercial (CC BY-NC 4.0) license, which permits others to distribute, remix, adapt, build upon this work non-commercially, and license their derivative works on different terms, provided the original work is properly cited, appropriate credit is given, any changes made indicated, and the use is non-commercial. See: http://creativecommons.org/licenses/by-nc/4.0/.

C Author(s) (or their employer(s)) 2021. Re-use permitted under CC BY-NC. No commercial re-use. See rights and permissions. Published by BMJ.

Open Heart 2021;8:e001442corr1. doi:10.1136/openhrt-2020-001442corr1

(A) Check for updates 